\title{
Strategies and International Universities Alliances to Cultivate International Students Studying in China under the Belt and Road Initiative to Develop New Talents
}

\author{
Huang Ting $^{1 *}$ Prasad Siba Borah $^{1} \quad$ Zhang Shibing $^{2}$ Wu Wenhao ${ }^{3}$ Shen Jiayi ${ }^{3}$ \\ 1. School of Management, Jiangsu University, Zhenjiang, China (212013) \\ 2. School of Mathematical Sciences, Jiangsu University, Zhenjiang, China (212013) \\ 3. School of The Belt and Road International Talents, Jiangsu University, Zhenjiang, China (212013)
}

\begin{abstract}
The Chinese Belt and Road Initiative (BRI) is a government-led development campaign to promote economic integration and infrastructure building in Eurasia and beyond, with the aim of reconnecting countries and enhancing prosperity in the historic Silk Road region to improve economic growth and exchange of talents. Since its inception in 2013, there has been a growing literature on the initiative, but educational studies in the context of the BRI have received relatively little study. Nowadays, most universities tend to join international alliances with other universities to expand their scope and promote exchange programs so that they can look more attractive and conquer the international market.This article aims to explore this relationship by conducting work through a combination of policy assessment, and empirical evidence from universities. Also, establish of a theoretical framework in terms of promoting educational policies and practices with respect to broader cultural policies to support the planning and development of the BRI. Given China's resurgence as a world power and its driving force in relaunching the Silk Road, this study contends that the strategic positioning of education at the BRI is a constructive force in the design, strengthening and implementation of the New Silk Road project. This reveals education and its many qualities to promote cultural dissemination, fulfill corporation commitments and accelerate economic growth in harmony with the general structure.
\end{abstract}

Keywords: The Belt and Road Initiative, Cultural policies, Education, International Students, Alliances

DOI: $10.7176 / \mathrm{JESD} / 12-24-02$

Publication date: December $31^{\text {st }} 2021$

\section{Introduction}

In 2013, during his visits to Kazakhstan and Indonesia, President Xi Jinping made a proposal that included the Silk Road Economic Belt and the 21st Century Belt and Road Initiative (BRI). In this context, the education of international students in China has become increasingly important, as the cultural exchange in the implementation of the BRI acts. In addition, as a bridge for communication between people from different places. After all, education provides intellectual support for networking in managerial corporation, infrastructures, commerce and finances. The BRI policies supports the education of international students in China. The Belt and Road countries have different resource allocations and very complementary economies, and there is great potential for networking and co-development. China will strengthen cooperation with Belt and Road countries by strengthening cooperation in diplomatic, infrastructural, commercial, financial and human fields with them. The interpersonal connection serves as a cultural foundation for the other four areas of cooperation and as a social foundation for the construction of the Belt and Road. China has a rich and deep historical and cultural heritage, unique academic cultural traditions and social customs with great respect for teachers and education; in such a favorable policy, China will attract even more foreign students. More foreign students will not only help "spread" China's deep and rich culture, but also promote colleges and universities, and improve the use of the belt and the road as a platform through which cultural messengers and international talents can better understand China and appreciate its culture. Figure 1 below shows the current roadmap of the BRI countries. 


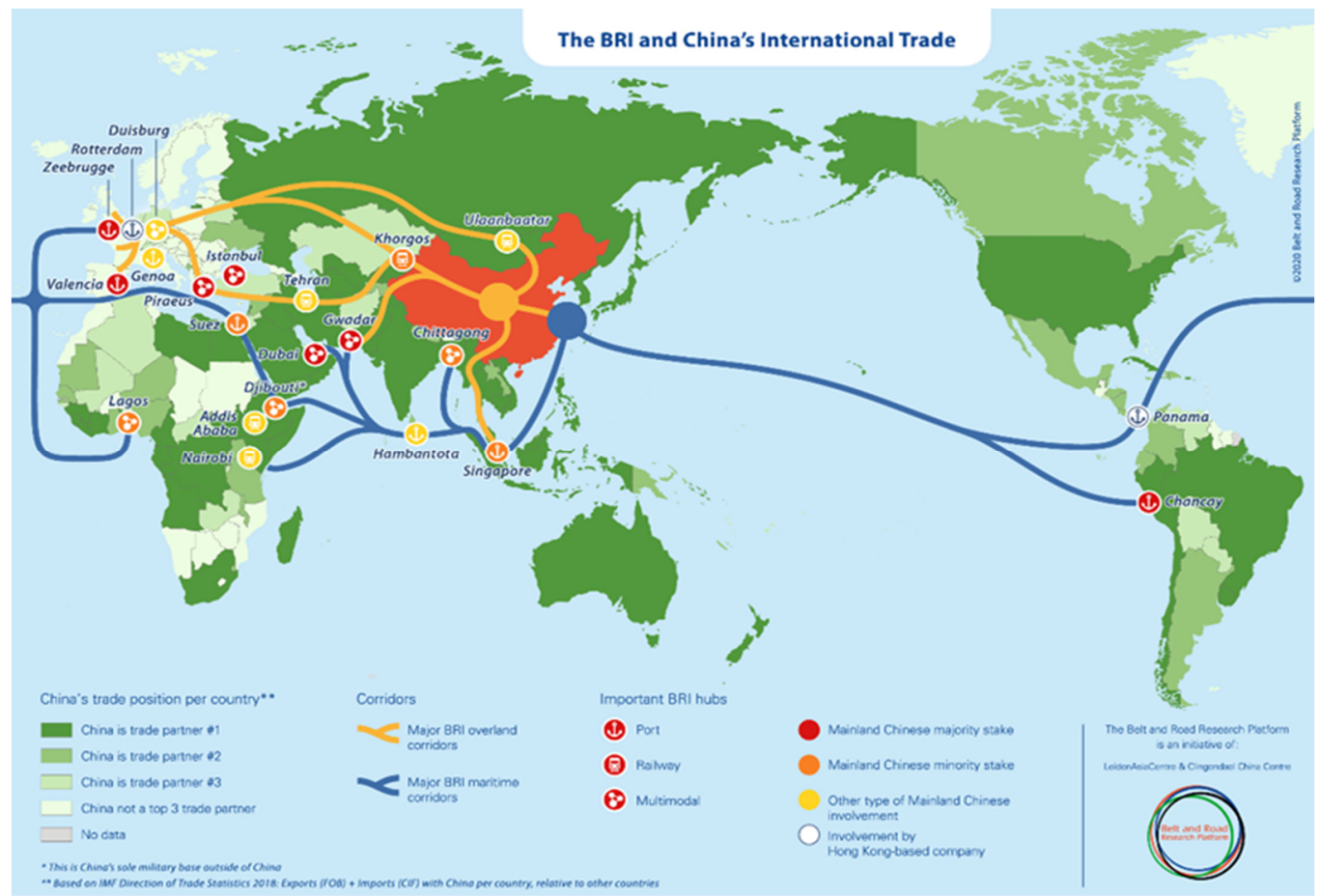

Figure 1 Belt and Road Initiative Roadmap (source: https://www.clingendael.org/publication/new-map-beltand-road-initiative)

The Belt and Road lines run through the continents of Asia, Europe and Africa, connecting the vibrant East Asia economic circle at one end and developed European economic circle at the other, and encompassing countries with huge potential for economic development. So many countries are along the lines with vast space, complex national conditions and a wide range of cooperation fields. Therefore, a large number of international talents with high professional quality, familiar with international laws and mastering multiple languages are urgently needed. In the construction of the Belt and Road, international talents will be the leading role to promote the implementation of various tasks. It is a common and pressing task for universities to train professional talents as needed. Embracing the spirit of the Silk Road, 'peace and friendship, openness and inclusiveness, mutual learning and mutual benefit', most universities vowed to build collaborative platforms in higher education and foster regional openness and synergies. They will advance institutional exchanges and partnerships on the Silk Road routes in regards to talent education, scientific research, cultural dissemination, policy studies, and medical service etc. They will also step up understanding and friendship between young peoples, foster quality and rounded talents with international visions, and stimulate economies enclosed on the Silk Road Economic Belt as well as the Eurasian region.

Colleges and universities have often had to emerge in response to changing social priorities, and over the past century there is a fierce competition due to an ever-expanding higher education system relying on important public investments. When companies are in need of more professionals in various field, they turn to universities to provide those experts. The introduction of internationalization and alliances among universities around the globe is dedicated to developing and implementing international talent partnerships among university and exchange knowledge to meet the demand of companies. These alliances help universities to improve their standards and expand their scope. This study examines how the education of international students in China can be developed by the BRI and further more highlights the importance of International Universities Alliances to create a better learning atmosphere.

\section{Literature Review}

\subsection{The Necessity of International Talent Training in Local Universities}

According to Su et al. (2020), with the implementation of the BRI strategy, new and more important demands have been placed on the cultivation of talents in universities. The talent development of colleges and universities actively responds to the national "Belt and Road Initiative" development strategy, not only the basic need for higher education reform, but also the implementation of the strategic need for "production" and "integration" of talent training. However, today, some colleges and universities still face issues such as inappropriate placement of talent, "how talent training works" and inconsistent needs, as well as inadequate staff training. Therefore, active measures should be taken to train academic talents to meet the needs of the BRI strategy: the goal of talent training should be established, the second is to create systemic training materials for universities, the third to improve the 
curriculum system for the training of students and a fourth to improve the teaching staff $(\mathrm{Bu}, 2020)$.

According to (X. Wang, 2019), learning for collaboration is crucial to build a country based on innovation. It is an effective way to improve the quality of education through interdependent learning between business, education and research, contributing to the development and renewal of early childhood students. Zhao (2019) analyzed the current state of collaborative training in local teacher education from a competency assessment perspective. There was a discussion of the internal and external factors that influence the depth of interdependent learning. Some of the specific recommendations stem from aspects of knowledge innovation, the role of leading authorities at all levels and the development of joint actions.

\subsection{The Effect of Cooperative Education under the BRI}

Erdogan (2019) assumed that collaboration and critical thinking would be important in 2020. In that sense, he examined the effect of cooperative learning, supported by reflective thinking activities, on international students. Given the challenges posed by climate change and related environmental pressures, a model focused on investing for sustainable development is needed by aligning investments with social and sustainable goals to ensure longterm prosperity and create sustainable growth among countries (Zhu \& Chen, 2019). The United Nations Sustainable Development Goals (SDGs) were published to guide countries towards green and sustainable development and to address public deficits. Per China's Belt and Road Initiative (BRI) requirement, a development strategy that includes investments in educational system, aims to promote international connectivity, integration of new talents and economic growth.

These two agendas share the concept of "sustainable development" and are becoming increasingly important (Inceoglu, Selenko, McDowall, \& Schlachter, 2019). While several studies have looked at the sustainability of the BRI, the implementation of the SDGs, and the similarities and complementarities between the two initiatives, few have addressed the possibility that the BRI can be a green and sustainable investment model by pursuing the SDGs (Erdogan, 2019).) has provided Chinese companies with significant incentives to accelerate the pace of internationalization. However, very little research on international trade has been shown to empirically examine these policy effects. Their study explored this important issue with the help of ethnic Chinese companies in the Xinjiang Uyghur Autonomous Region (XUAR) in China. They proposed that BRI has a positive formal institutional effect on the export performance of XUAR companies going to the "Belt and Road Initiative" countries. Cultural frictions and ethnicity act as unique cultural events that moderate the relationship between BRI and export performance.

\subsection{International Talents Adapt on the Field of Financial Integration}

Financial integration is an important support for The Belt and Road construction. China's financial industry needs to adopt a more active attitude to adapt to international competition rules (A. Peters et al., 2020). According to Li (2020), there is a need to focus on promoting cooperation and development in fields such as the monetary stability system, the investment and financing system, bilateral currency swaps, the opening of the bond market, the Asian Infrastructure Investment Bank (AIIB) and the New Development Bank. Thus, the international talents needed are mainly financial related.

With the deepening of vocational training reform and the development of new technologies, the economic environment for businesses and institutions has changed significantly. At the same time, after the pilot implementation of the " $1+X$ certificate" by the Ministry of Education, traditional training in financial management can no longer meet the requirements of the new situation. J. Wang (2021) reflected on how we can overcome the bottleneck in financial management course development, strengthen cooperation with companies, implement manufacturing and training integration, and provide high quality and targeted financial management talent with expertise with the "big financial system" and an international vision. According to Crowley - Henry, Benson, and Al Ariss (2019), Talent Management (TM) is a growing industry that emphasizes optimizing human resources to create sustainable competitive advantage for businesses. Although successful TM practices are widely understood as career development, the topics of career and TM remain largely separate in the human resource management (HRM) literature.

By the end of July 2020, the AIIB members have reached 103, more than $71 \%$ from Belt and Road countries. In addition, in 2018 it has launched 28 projects in 13 countries with a commitment of more than 11 billion US dollars, covering all Belt and Road-related countries and regions. 92\% of central Banks from representative 26 countries predicted that the Belt and Road programs would support domestic economic growth over the next five years, with a majority of respondents saying that it would boost annual growth by nearly one percentage (Herrero $\& \mathrm{Xu}, 2019)$. The AIIB involves many countries and has a complex capital chain, so its operation and management inevitably need a large number of high-level international financial talents and the establishment of international universities alliances. 


\subsection{International Talents Adapt on the Field of People-to-People Bond}

People-to-people bond is the social and cultural foundation for The Belt and Road construction. It is the foundation for strengthening national understanding and deepening cultural integration. It is also the basis for policy coordination, facilities connectivity, unimpeded trade and financial integration. Carrying forward the spirit of friendship and cooperation along the silk \& road and carrying out extensive cultural, academic and personnel exchanges are the solid foundation for promoting bilateral and multilateral cooperation (Drewery, Pretti, \& Church, 2020). The international talent demand is mainly reflected in education, culture, tourism, medical treatment, health care, law, employment and so on.

By the end of April 2018, China had established 1023 friendly cities with 61 "Belt and Road" countries, accounting for $40.18 \%$ of the total number of international friendly cities in China. In 2017, China's two-way tourism with the Belt and Road countries reached 60 million person-times. The "Belt and Road" tourism became a new growth points for world tourism (Smith, 2018). According to the statistics of the Ministry of Education, China has established 17 national cultural centers and 173 Confucius Institutes in the Belt and Road countries (Ahmad \& Shah, 2018). Every year, the Chinese central government provides 10,000 government scholarships to relevant countries, and local governments have set up special silk \& road scholarships, which have supported a large number of leading and skilled talents from Belt and Road countries. International tourism along the Belt and Road lines accounts for more than 70 percent of the global total income. From 2011 to 2016, 150 million Chinese tourists have spent 200 billion US dollars on countries along Belt and Road (Xu, Hsu, Meen, \& Zhu, 2020).

\section{Research Methodology and Question Development}

To conduct this research, the primary research methodology was conducted by a comparative study on previous literature reviews. These data were based on the theoretical framework for existing academic papers and public information from the government official website. The research provides suggestions for determining the cultivation strategy of international students at Chinese universities as part of the Belt and Road Initiative and also the promotion of international universities alliances.

In addition, this study analyzes and finds answers to these claims. According to the results, the work leads to a discussion, in particular about how the qualities of the culture of international students are limited by the following aspects: e.g. easing the enrollment conditions, improvable approaches in culture and competence management, limited courses and disciplines and a dramatic impact of Covid-19 pandemic. Although there are many strategies to encourage international students to study in China, this study mainly focuses on strict enrollment control, improving curriculum design, building teaching staff, system development program, improving management and service skills, encouraging international alliances and adapting to new changes caused by the pandemic.

Question 1: What are the field of study most needed for international students studying in China to enroll in the view of The Belt and Road Initiative?

Question 2: What are the specific problems that Chinese universities are facing in cultivating international students studying in China?

Question 3: What are the appropriate cultivation and international alliance strategies for Chinese universities adopted for international students studying in China?

Question 4: What is the role of international universities alliances in the development of BRI talents?

\section{Case Study Analysis}

\subsection{Policy Guidance for International Students Studying in China in the Post-Epidemic Era}

In April 2020, more than 1.5 billion students in nearly 190 countries were affected by school closures caused by the pandemic of COVID-19, representing $90 \%$ of the world's students and an unprecedented situation in the history of education. The top 10 countries with suspended students are China, Pakistan, Bangladesh, Egypt, Turkey, Ethiopia, Iran, Japan, France and Thailand. In response to the call of the Ministry of Education to ensure the suspension of classes during the postponing-term period, universities across China have set up "classroom online", synchronizing part of the on-campus course resources to the online teaching platform for students to learn, and providing online education services for students through the national education resources and public service cloud platform. The main policy guidance is to strengthen education on China's national conditions for international students and form international universities alliances for a win-win situation.

China will promote the reform and innovation of national conditions education courses, textbooks and teaching methods for international students, continue to support the construction of high-quality national conditions education courses and English courses, and promote and share high-quality courses online. In addition, continue to carry out brand activities such as "Experience China" to help international students learn more about China's history, culture and economic and social development. International students are encouraged to use short videos, photos, articles and other ways to actively show their learning and living experiences, and what they have seen and heard in China. Figure 2 below shows funding by China's Ministry of Education in 2018, where they 
funded about 3.3 billion yuan on international students.
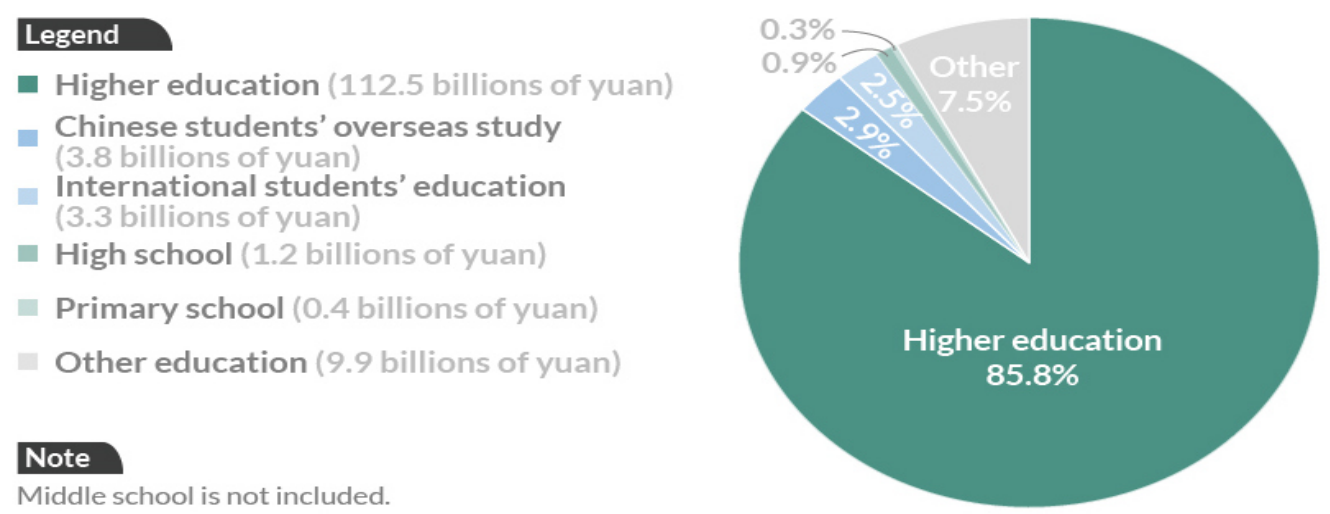

Figure 2 Pie Chart of Fundings from China's Ministry of Education (source: China's Ministry of Education 2018)

\subsection{Coordinate Epidemic Prevention and Development of International Students}

In the context of the COVID-19 pandemic, universities actively explore the integration of online and offline education in the post-epidemic era, promote the reform of education concept and model innovation of international students in China under the condition of "Internet Plus". It encourages universities to make full use of online education to attract high-quality international students, innovate the training model, strengthen the construction of brand courses by joining international universities alliances, realize the sharing of high-quality course resources, and seize the territory of online education.

Improve the quality of international students in accordance with laws and regulations. The policy system has been constantly improved to provide legal guarantee and norms for studying in China by adhering quality first to improve the quality of assurance system in terms of internationalization. It is important to urge universities to implement the Measures for the Administration of Enrollment and Cultivation of International Students studying in China and the Quality Standards of Higher Education for International Students studying in China. Strengthening the construction of the faculty \& management team and the "Study in China" brand, the cultivation goal is to strive to build a global education center with international influence and a destination country for excellent young people to study abroad and also create a suitable environment for international universities alliances.

\subsection{Case Analysis Findings}

The overall economic strength of the Belt and Road countries is relatively weak. These countries are always eager for qualified talents. Nevertheless, the international talents cultivation in China is still difficult to meet their needs. The number of talents is insufficient, and the cultivation direction cannot fully match the "five links" construction. Figure 3 below depicts the mobility of students' enrollment under the BRI.
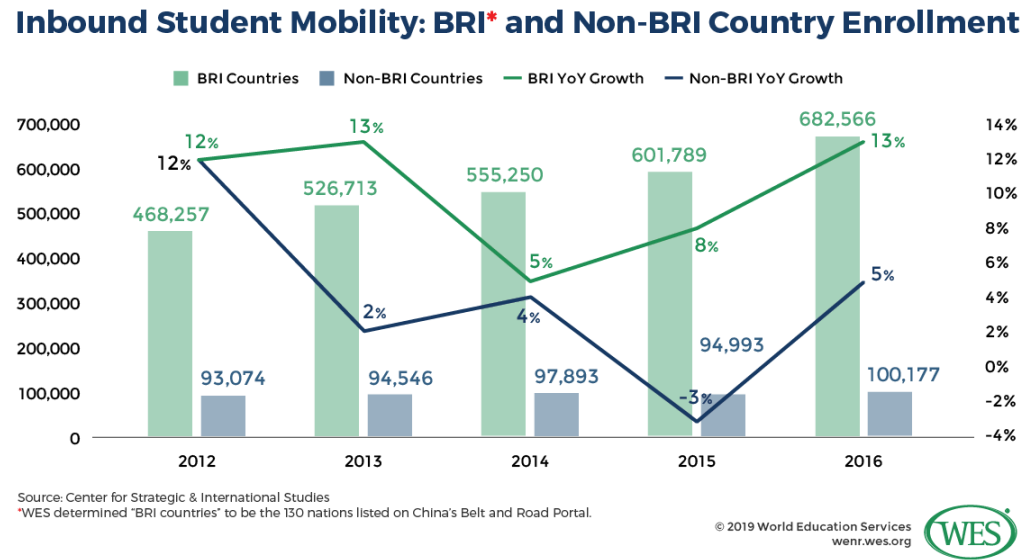

Figure 3 International Students Inbound Mobility Comparison between BRI and Non BRI countries (Source: World Education Services)

From Figure 3 we can observe that there is a huge flow of international students under the BRI, which means 
that the BRI has significantly attracted more talents to come and study in China over the past decade.

\subsubsection{Relaxation of Enrollment Requirements}

Although the Ministry of Education formulated the Measures for the Administration of Enrollment and Cultivation of International Students studying in China in 2017, and the Quality Standards of Higher Education for International Students studying in China pilot test in 2018. However, due to the large difference of the provincial economic and social development, the two fundamental laws are overview and sweeping, lack of practical guidance, requiring regional provinces formulated their own. However, most provinces have delegated relevant rights to colleges and universities, so the problem of inconsistent core standards for education, enrollment and training of international students has not been fundamentally solved.

At present, there is still no unified entrance examination system for international students in China. The enrollment right mastering by every university, so it lacks a substantial regulatory assessment mechanism and some universities are in lack of necessary requirements and they only pursue the growth of the number of international students' intake. Under the background of "Double First-class" construction, in order to improve the level of internationalization and strive for the advantage of discipline evaluation, more universities focus on expanding the scale of international students, and then relax the enrollment requirements. As a result, there are a large number of international students enrolled in China on the surface, but fewer of them actually meet the graduation requirements, the degree-awarding rate is low. Therefore, the number of international students meeting the requirements of the Belt and Road construction is in short supply.

In this context, when it is difficult for one university to set its own standards for international student recruitment, the International Universities Alliance can play a good role. The alliance is usually composed of several domestic universities and several foreign universities due to the same similar disciplines or common goals. At this time, joint recruitment expert group can be set up to jointly formulate recruitment requirements in line with international standards, so as to better select international students.

\subsubsection{To be Improved Cultivation Approaches}

As for the teaching contents and methods, many universities still engage in the education of international students according to the training requirements of local students by mainly adopting the formal academic training mode. However they lack of providing industrial practice and internship to international students, causing the restriction of international students' education certificates out of step with employability to some extent due to those challenges. In addition, the corresponding training programs, curriculum systems and teaching plans have not been designed according to the characteristics of the Belt and Road students. For example, most of the Belt and Road countries are developing countries, and their basic education level is relatively low. International students from these countries are generally poor in basic subjects such as advanced mathematics and physics. If the international students are treated in the same teaching requirements as for local students, it will greatly affect the teaching performance and their graduation quality.

On the other hand, from the perspective of the faculty, teachers who truly master English, familiar with the characteristics of students along the Belt and Road and able to teach students in accordance with their aptitude are still few. Jiangsu Province is one of the most developed provincial areas in China among 34 provinces (autonomous regions and cities), and the numbers of international student is the $3^{\text {rd }}$ in China. Taking Jiangsu Province as an example, although the number of international students has grown steadily, and the quality of English teaching has been continuously improved in recent years. However, the speed of teachers has not kept pace with the expansion scale of international students, and the teaching level and ability have not reached the expected level.

Limited Professional and Functional Courses International students from the Belt and Road countries are generally expected to obtain better job opportunities and career promotion. Therefore, most of the majors selected by students are concentrated in the popular field. The higher education quality in Jiangsu Province is Top 3 in China. Compared with 2013, the total number of international students studying in Jiangsu Province in such majors has increased by more than $50 \%$ in 2017 . However, we could find those majors that are also very important to the development of Belt and Road countries still having not been covered like public health, military science, international law, mass media, city planning, and course construction are really rare so far. 


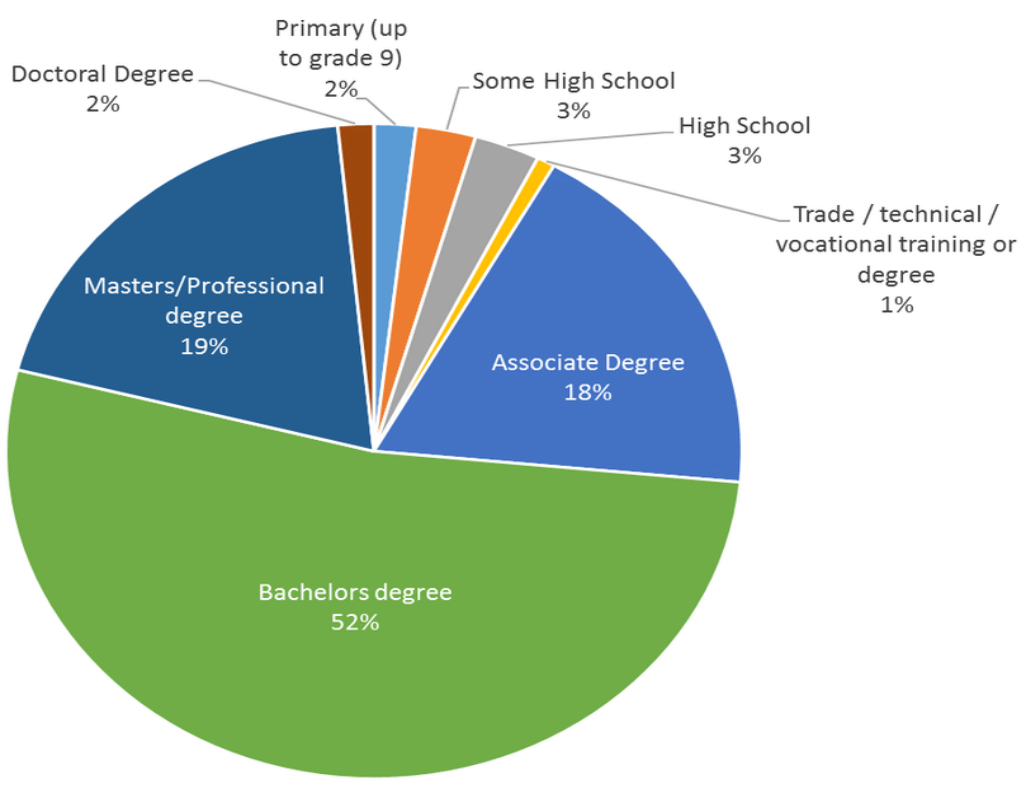

Figure 4 Proportion of Enrollment Program at the university

Figure 4 above shows the various program offered at the university, we could observe that the majority of the existing programs are favorable for undergraduate studies. However, there are few doctoral programs limiting the scope of studies.

Table 1 Main majors and numbers of International Students Studying in Jiangsu Province, China

\begin{tabular}{|l|c|c|c|c|c|}
\hline \multicolumn{1}{|c|}{ Yeajor } & 2013 & 2014 & 2015 & 2016 & 2017 \\
\hline Medicine & 3714 & 4108 & 4256 & 4580 & 4916 \\
\hline Engineering & 1835 & 2151 & 2277 & 3107 & 3970 \\
\hline Chinese language & 8069 & 8522 & 8995 & 11096 & 11748 \\
\hline Economics & 742 & 785 & 1015 & 1230 & 1606 \\
\hline Management & 412 & 649 & 913 & 1319 & 1694 \\
\hline
\end{tabular}

\subsubsection{To be Improved Management Ability}

Due to the lack of access mechanism, unclear positioning and the convergence of educational objectives, there are problems such as disorderly competition, ecological niche overlap, and unreasonable structure in the international students' cultivation in some Chinese universities. In this background, the continuous investment in the education development of international students is indifferent, especially in the allocation of international resources for teaching, management and service is seriously lagging behind, which directly affects their living, learning and experience in China and the improvement of education quality. Unclear responsibilities of different functional departments, lack of communication and coordination, resulting in the educational management confusion of international students, mutual buck-passing and other phenomena occur.

In addition, as managers and service of the international student's daily affairs, the overwhelming majority of international students' counselor team is insufficient, unprofessional, lack of career guidance ability, which caused part of the foreign student's learning experience a direct negative impact. Then it is difficult for some international students along the Belt and Road to integrate into the university environment and Chinese society, and the gap between expectation and reality is too large to solve psychological problems, which may lead to behavioral deviation.

Universities patterning to the "International Universities Alliance" can learn from each other's advanced management experience. Foreign universities have lots of experiences, which are worth learning for Chinese universities in terms of management system design, functional departments division, student services, employment guidance, psychological counseling, internship opportunities and alumni liaison and so on.

\subsubsection{Dramatic Impact of COVID-19 Pandemic}

Student mobility has been generally affected and the international education sector has been hit hard since 2020 . Global higher education as we know has forever changed. Until September 2021, for the big pressure of COVID19's raging abroad, Chinese government doesn't open the border for international students still staying abroad, thus all universities provide online teaching for them to complete their studies per their initial schedule. More than half-international students have to study online. Chinese universities are teaching by remote learning, have 
achieved great performance, and accumulated a lot of experience, which is impressive. However, Most of the Belt and Road countries have weak economic conditions and poor internet and other infrastructure, the quality of remote teaching is restricted by these external factors, so student satisfaction is greatly reduced. The decline in global gross domestic product is another serious problem and has a very negative impact on international students, whose ability to pay for tuition, travel and living expenses get worse and worse.

\section{Discussion}

In view of the above analysis combined with the reality of Chinese higher education development, we explore the approaches of sustainable development for international students' cultivation of Chinese universities.

\subsection{Optimize the enrollment scale and structure while improving the cultivation criteria of international students}

The proportion of international degree students in world first-class and famous foreign universities is very high, such as University of Cambridge is $37 \%$, University of Oxford is $32 \%$, but Tsinghua University and Peking University of China are both $6 \%$. In order to serve the blueprint of major-country diplomacy with Chinese characteristics and build a community with a shared future for humankind, it is the responsibility of Chinese universities to steadily increase the enrollment scale, attract and cultivate more outstanding international students. Therefore, universities should further expand the proportion of students along the Belt and Road, increase the proportion of science, engineering, medical, law and economy students, and increase the proportion of postgraduate students.

Firstly, the central government should improve the contents of the measures for the schools' management and cultivate the integration of international students. In addition improve the Quality of Higher Education specification for International Students studying in China. Formulate the specific recruitment of international students, specify the training and graduate standards at national levels, and distinguish the categories of degree and non-degree students. Secondly, according to the basic national standards and the actual situation of international education orientation, training resources and teaching staff, each university sets its own standards to improve the quality of international students. Based on strengthening the daily teaching management $\&$ service, and rights protection, universities should encourage the recruitment of high-level international students from the Belt and Road countries and all over the world.

Finally, in order to cultivate more young elites and future leaders of Belt and Road countries, there is a need to focus on the overall recruitment requirements to improve the quality and efficiency of international students. Universities should coordinate the establishment of a training system on the premise of standardized selection examination and sustained by conducting specialized entrance examination. In addition, there is a need to set teaching guidance and reform the selection and management of scholarship. In addition, promote the convergence of study and life services for international students and Chinese students, as well as work-study, internship and employment and "zero tolerance" for illegal behavior. These measures could be developed through international university alliances.

\subsection{Improvement of the training plan design and building comprehensive faculty staff's diversity system to improve the quality of teaching}

The quality of international students' cultivation depends largely on the high-quality training plan especially the faculty staff level. Countries along the Belt and Road have strong regional characteristics. In addition, Chinese universities also have obvious regional characteristics and advantages. In this regard, universities should build internationally competitive advantages and distinctive disciplines with precise academic education for international students from countries along the Belt and Road, and combine the actual needs of international students to create Belt and Road distinctive brand projects.

As we know, Peking University and Tsinghua University are the best top two universities located in the capital of China. Their history, geographical and resource advantages make them the most advantageous universities in terms of policies, management, economy, diplomacy and other aspects in China. Yenching Academy of Peking University (YAPU) and Schwarzman Scholars of Tsinghua University (SSTU) are comprehensive colleges for cultivating international talents. Their training plan are to initiate true internationalization covering global multipolar human science and multiculturalism, and vigorously carry out "local internationalization", give prominence to humanities and social sciences. In addition, focus on China studies whereby students are trained to develop global citizenship, international understanding, and leadership.

The proportion of international students in 2016 of YAPU is $83 \%$ and SSTU is $79 \%$. YAPU has a faculty of 70 members, 30 of whom are Peking University's Chinese and foreign professors, 20 of whom are internationally recruited staff, and the rest 20 are invited top international visiting professors. SSTU's faculty has 16 Tsinghua University's Chinese and foreign professors and 38 academic experts and industry elites from all over the world.

Both YAPU and SSTU focus on Chinese studies and provide students with opportunities to understand China. 
YAPU offers six direction of training plan: Human Relationship Science and International Relations, Law and Society, Economics and Management, Philosophy and Religion, Literature and Culture, and History and Archaeology. SSTU offers three: public policy, economic management, and International Studies. In addition, two colleges also emphasize design study, field investigation and practice, organize students to the relevant enterprises, rural areas, ethnic minorities regions, grassroots community, pension institutions, and government departments to carry on the discussion, communication and thinking to explore the highlight of China's development model and features.

\subsection{Strengthening the curriculum by building a system based on advantages and the creation of alliances among universities}

When preparing courses, YAPU and SSTU combine the cultivation of international students with the improvement of the international reputation of the university, and integrate many thoughts on the internationalization development of higher education in China. The outstanding performance is to carry out "self-centered internationalization" based on their traditions and the dominant position. YAPU offers courses such as China in Transition, Field Research, China Lecture Series, History \& Archaeology, and Human Resources \& International Relations. SSTU offers courses such as Global Affairs, Forty Years of Chinese Policies Implementation, Economic, and Social Reform, Leadership in Public Organization, Leading in Crisis and Disasters, and Deep Dive.

Apart from universities located in Beijing, Chinese universities in other regions should choose the key Belt and Road countries for research and design special courses, considering their proximity to Belt and Road countries ( similar culture and customs) and economic \& trade ties (solid foundation of cooperation). Universities in Shanghai, Guangdong, Fujian, Zhejiang, Jiangsu provinces should focus on central and Eastern Europe, West Asia, and Africa. Universities in Yunnan, Guangxi and Guizhou provinces should pay attention to Southeast Asia, those in Chongqing on South Asia, those in Xinjiang, Tibet and Shaanxi provinces on Central Asia, and those in Jilin, Liaoning and Heilongjiang provinces on Russia and Mongolia.

As the best university in Jiangsu province in terms of international students, Jiangsu University's experience is also worth learning. (1) Make great efforts to build national and provincial excellent English courses. In 2020, 4 English-language courses were approved for national-level quality courses including International Trade, and 25 English-language courses were approved for provincial-level quality courses including Physical Chemistry, Probability theory and Mathematical statistics and so on. (2) Promote integration of industry and education. On December $10^{\text {th }}, 2016$, Jiangsu University's the Belt and Road International Talent Training Industry Alliance was established.

Jiangsu University established the first batch of more than 40 enterprises joining to participate in international students' order-based training. Jiangsu University's President Prof. Yuan Shouqi, Chairman of the alliance said, "With the establishment of the industry-education alliance as an opportunity, Jiangsu University will attract enterprises and industry organizations to participate in the whole process of international talents training. Including jointly formulating training objectives, training specifications, professional teaching standards and Curriculum standards with practical opportunities to study international market needs and expand international markets." Until 2020, it has over 110 enterprises joining the alliance. (3) Hold the academic international forum for students. In terms of academic exchanges, the annual "Chinese and International Postgraduate Academic Salons" is held regularly to stimulate the enthusiasm of international students, demonstrating their ability to collect information and be willing to express their own expertise and enhance the academic major of international students.

To enhance diversity, Jiangsu University joined hand with various universities all over the world to create international universities alliances under the BRI where they can exchange knowledge and also promote higher education that can attract more international students. Jiangsu University represents one of the first universities in the Jiangsu province to establish such alliances to enhance a win-win situation under the BRI.

\subsection{Efficient improvement of management and service capacity}

Attach importance to the construction of international student counselors to assist them. International student counselors' responsibilities are not only based on their daily management transaction and services, but also lead and shape of international students' ideology, moral character, legal concept and civic consciousness of Chinese culture. There is also a need to integrate the liaison of international alumni, the mentor and practitioner of the integration of Chinese and foreign students, the disseminator of Chinese voice and the narrator of "China story". First, international student counselors should be equipped, aiming at a 1:120 teacher-student ratio. Secondly, we should strengthen the construction of counselors' professional ability. The University of California, Berkeley, has developed standards for the behavioral quality of student affairs staff, including the professional ability grades and explanations of communication skills, professional knowledge, problem solving/innovation, work output and quality, self-management ability, interpersonal communication, teamwork and other aspects. Chinese counselors are required to improve their accomplishments in communication skills, professional knowledge (career guidance), problem solving and teamwork. 
In addition, due to the huge difference between international students and Chinese students, as well as the overall low foreign language communication ability of the counselors, the student affairs system of most Chinese universities does not include international students, which are managed by the school of International Education and other specialized secondary units. Therefore, it is urgent and necessary to integrate the international student work into the university student work general system, formulate and improve the documents of international student affairs. Specifically, it should be guided by the concept of "combining convergence and differentiation management for all-round improvement". In addition, form a collaborative working mechanism covering all international students with the International Office, Student Affairs Office and Graduate Affairs Office as the business guidance departments, relying on the student work team of the college and school, give full play to the professional service capabilities of psychological counseling, career guidance, learning and global competency development departments.

\subsection{Weaken the Impact of the Pandemic by Adopting new Learning Policies}

Because of COVID-19, there is full of new changes in educational concepts, connotations, methods, relationships and participants. Online education will become a trend, students do not have to stay on campus or even in the same country, and teachers' thinking mode and teaching behavior need to be changed. Higher education must quickly adapt to new changes such as "online education" and "homeschooling" in the post-pandemic era. A plan to improve education governance capacity in the "post-crisis era" should be formulated as soon as possible to accelerate the construction of a modern education governance system to cope with public social crisis. In response to the Covid19 pandemic, the measures taken by education systems and education administrative departments of various countries largely reflect that different educational governance subjects are not fully equipped with the education governance ability to deal with the public social crisis.

Therefore, first, we should enhance the ability of risk prediction and research of education crisis; secondly, improve the ability to deal with the risk of education crisis; finally, we should develop the awareness and ability of education to deal with public social crisis. Only in this way, education governance can change from fuzzy to clear; from uncertain to definite, highlight the characteristics of legal, institutionalized and standardized education governance system, and establish a normal crisis response mechanism. On the premise that the global pandemic is effectively controlled and the safety of overseas students is guaranteed, China still needs to continue to expand the opening up of the higher education sector to provide and create more opportunities for students to study in knowledge-leading countries such as the United States, Japan, the United Kingdom and France.

\subsection{Strategies to improve international universities alliances}

Colleges and universities have a long history of collaboration through trade agreements, sharing of resources, coordination of research programs (e.g. programs and research agreements) exhibition, sporting events and research. There is a significant difference between these traditional associations and the awareness programs in this study. The former often works in nature and cares more about the good (whether or not to improve things) than the good (creating new businesses in response to a changing environment). Expanding and strengthening the capacities of existing partners, examples of such guidelines are the sharing of library resources, shared purchasing, or student enrollment.

Academic alliances relies on the ability of partners not only to classify processes and practices, but also to understand and respond to multiple standards and expectations. The use of organizational culture literature examined the factors that influence these relationships. Organizational culture is "a set of non-disciplinary measures of organizational behavior and the exchange of values, ideas, beliefs or opinions of people as a whole" about its organization or its function. Figure 5 below shows the steps universities can adopt to achieve a successful alliance. 


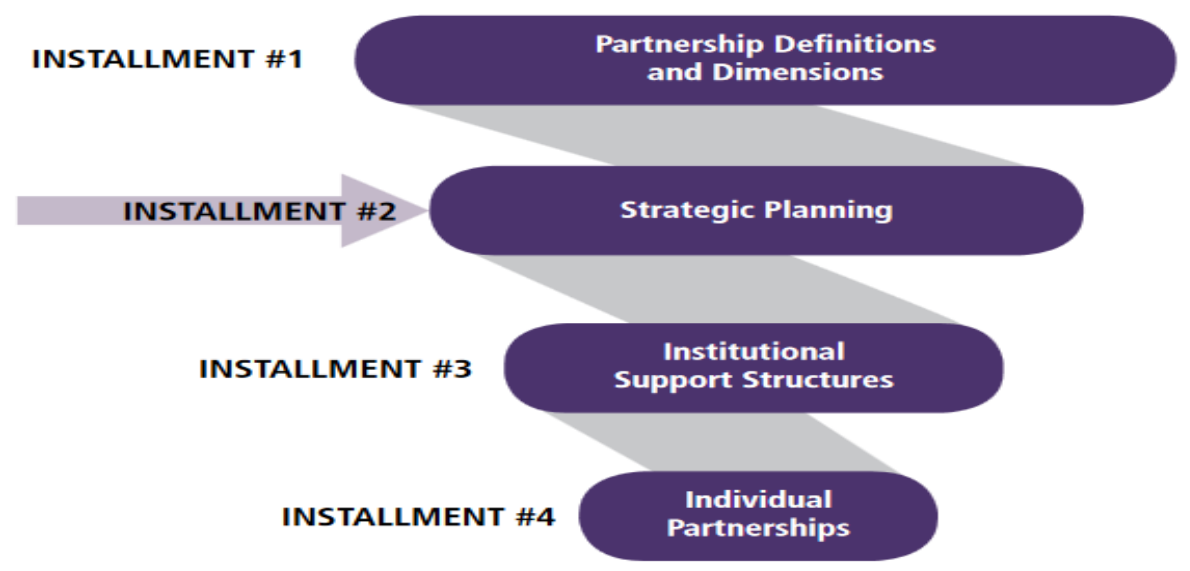

Figure 5 Strategies to achieve international alliances

- Connect partnerships to institutional strategy: Partnership Definitions and Dimensions plan of the university as a whole. In some colleges and universities, internationalization is presented as a specific goal or clearly demonstrated in long-established goals (eg, "preparing students for the international world of the 21 st century"). With these, many organizations have taken a step further by developing an international strategic plan that fits with the organization's overall strategy and guides the dissemination process.

- Assess the current state of internationalization: Strategic Planning, after considering how the partnership fits into the overall organizational strategy, the next step is to focus in particular on internationalization and examine how to develop and support international partnerships. Understanding the international status of the campus will help organizations identify specific areas - for example, research programs, student transfers, education, training, and research - that may benefit from new or enlarged partnerships. It will also identify key elements of partnership development and implementation, such as who should be involved on campus and what new capacities may be needed to support the process.

- Take stock of existing collaborations: Institutional Support Structures, while internationalization can already include cooperation with foreign partners, the institution and its affiliates may not have accurate information about formal links and reviews that already exist. An analysis of existing international relations will be carried out to develop a partnership for the future. There is also a need to establish International Headquarters (also known as the International Headquarters Office) that can gather accurate data concerning the alliances.

- Analyze the environment: Individual partnerships, after examining the feasibility of developing an international partnership, national plan, there is an in-depth study of factors that may affect the viability of these relationships and their success in contributing to the achievement of organizational and international goals. The SWOT (Strengths, Weaknesses, Opportunities and Threats) framework provides a useful guideline for the analysis, which should incorporate and build on the data and four pieces of information obtained from levels 1 to 3. This exercise should focus on the questions of partnership but not across the organization.

\section{Conclusion}

The increase in economic and people -to -people exchanges between China and BRI countries has enabled many students from these countries to improve their skills and master Chinese language and culture successfully. These students represent the messenger of Chinese culture to the rest of the world, and also constitute the potential talent who can effectively implement the knowledge they acquired while studying in China to their respective countries to achieve an efficient development growth. Based on the establishment of international universities alliances, Chinese universities will gain more popularity and attract more scholars and boost the R\&D talent of China and BRI countries.

The Belt and Road Initiative is an important opportunity to develop university international students' cultivation in China. Even though facing so many challenges, all universities should seize the opportunity based on their advantages and characteristics. They should vigorously develop and improve quality and efficiency of international students' cultivation by joining and learning from international universities alliances. Specifically, it is very necessary to optimize the enrollment scale and structure while improving the cultivation criteria, improve training plan design and faculty staff construction, strengthen curriculum system construction based on advantages, improve management and service capacity, and weaken the impact of the pandemic. Chinese universities could provide enough intellectual support coming from international students for the Belt and Road construction and 
also join international universities alliances to promote the inflow of international students by instituting on exchange programs to promote Chinese culture to the world.

\section{Acknowledgements}

The authors would like to thank anonymous reviewers for their valuable comments. We also wish to thank the Overseas Education College and academic schools of Jiangsu University for their valuable support.

Funding and Grants

Social Science Foundation of Jiangsu Province (17JYD002); Special Project of "Double First-class" Construction and Internationalization of Higher Education of China Association of Higher Education (2019SYLZD09).

\section{References}

1. A. Peters, M., Oladele, O. M., Green, B., Samilo, A., Lv, H., Amina, L., . . Rulin, X. (2020). Education in and for the Belt and Road Initiative: The pedagogy of collective writing. Educational Philosophy and Theory, 52(10), 1040-1063.

2. Ahmad, A. B., \& Shah, M. (2018). International students' choice to study in China: an exploratory study. Tertiary Education and Management, 24(4), 325-337.

3. Bu, H. (2020). Research on the Improvement of Local Colleges' Talent Team Construction from the Perspective of "Double First-Class". International Journal of Nonlinear Science, 30(1), 19-24.

4. Crowley - Henry, M., Benson, E. T., \& Al Ariss, A. (2019). Linking talent management to traditional and boundaryless career orientations: Research propositions and future directions. European Management Review, 16(1), 5-19.

5. Drewery, D., Pretti, T. J., \& Church, D. (2020). Contributions of work-integrated learning programs to organizational talent pipelines: Insights from talent managers. International Journal of Work-Integrated Learning, 21(3), 275-288.

6. Erdogan, F. (2019). Effect of cooperative learning supported by reflective thinking activities on students' critical thinking skills. Eurasian journal of educational research, 19(80), 89-112.

7. Herrero, A. G., \& Xu, J. (2019). Countries' perceptions of China's Belt and Road Initiative: A big data analysis. Retrieved from

8. Inceoglu, I., Selenko, E., McDowall, A., \& Schlachter, S. (2019). (How) Do work placements work? Scrutinizing the quantitative evidence for a theory-driven future research agenda. Journal of Vocational Behavior, 110, 317-337.

9. Li, H. (2020). How to Retain Global Talent? Economic and Social Integration of Chinese Students in Finland. Sustainability, 12(10), 4161.

10. Smith, J. (2018). China's Belt and Road Initiative: Strategic implications and international opposition. Backgrounder(3331), 2018-2008.

11. Su, J., Randall, P., Lartey, F., Tate, T., Sakyi, K., \& Tayali, E. (2020). Research on talents training in colleges and universities under the background of 'Belt and road'strategy. Journal of Human Resource Management, $8(3), 109-114$.

12. Wang, J. (2021). Construction of the practice course system of the major of financial management under the mode of University-enterprise cooperation - take Sichuan University of arts and science as an example. Open Access Library Journal, 8(01), 1.

13. Wang, X. (2019). Research on Industry-University-Research Cooperative Education of Local Normal Universities in China from the Perspective of Teaching Assessment. Open Access Library Journal, 6(04), 1.

14. Xu, H., Hsu, W.-L., Meen, T.-H., \& Zhu, J. H. (2020). Can higher education, economic growth and innovation ability improve each other? Sustainability, 12(6), 2515.

15. Zhao, G. (2019). Analysis on the transitional development of entrepreneurship education in colleges and universities in the age of mass creation. Paper presented at the 5th International Workshop on Education, Development and Social Sciences (IWEDSS 2019).

16. Zhu, L., \& Chen, Y. (2019). Dovetailing the Belt and Road Initiative with the 2030 Agenda for Sustainable Development: The Connotations, Objectives and Pathways. Chinese Journal of Urban and Environmental Studies, 7(01), 1940005.

17. http://www.moe.gov.cn/jyb_xwfb/gzdt_gzdt/s5987/201904/t20190412_377692.html.

18. Curriculum System of Yenching Academy of Peking University [EB/OL]. (2021-09-07)

19. https://yenching.pku.edu.cn/kcsz.htm\#79

20. The Belt and Road Big Data Report on Trade Cooperation 2018 [EB/OL]. (2018-05-08) http://www.sic.gov.cn/News/553/9207.htm.

21. Grasp the New Mission to Promote the New Development Of Study in China [EB/OL]. (2021-07-23)

22. http://www.moe.gov.cn/jyb_xwfb/moe_2082/2021/2021_zl48/202107/t20210723_546313.html 
23. Which UK Universities Have the Most International Students [EB/OL]. (2020-08-07)

24. https://zhuanlan.zhihu.com/p/171582924

25. The Belt and Road Big Data Report 2018 [EB/OL].

$(2018-09-22)$ http://aoc.ouc.edu.cn/39/53/c13996a211283/page.psp.

26. [10]Data Shows How The Belt and Road Initiative Connects the People [EB/OL]. (2017-05-05) http://www.xinhuanet.com/video/sjxw/2017-05/05/c_129590839.htm

27. Cao Bufeng. Research on the Problems of International Students Education Development [J]. Yangzhou University Journal, 2011, 15(5): 44-48.

28. Jin Min. Research on the Development Strategy of International Students Studying in Jiangsu Province [J]. Yangzhou University Journal, 2018, 8 (4): 42-45.

29. Zhou Yuefeng. The Impact of COVID-19 on the Internationalization of Higher Education [J]. Journal of World Education, 2020(5):13-15

30. Brief introduction to Peking University [EB/OL](2019-12-31)

31. http://www.isd.pku.edu.cn/lxsq/gk.htm

32. New Trend of Internationalization Development of Chinese Universities [J]. Education Research Monthly, 2017(5): 14-19.

33. Curriculum System of Schwarzman Scholars of Tsinghua University [EB/OL]. (2021-09-08)

34. http://www.sc.tsinghua.edu.cn/course/index.jhtml

35. Policy Research on Education Development of International Students in Chongqing under the Background of the Belt and Road [J]. Chongqing Higher Education research, 2021(9): 13-24.

36. Quality Report on International Students Education in Jiangsu University of 2020 [R].Overseas Education College, Jiangsu University.

37. Wu Wenhao, Xie Zhifang. The Role Orientation and Achievements of International Student Counselors in The Process of Education Opening to the Outside World [J]. Heilongjiang Researches on Higher Education, 2020(10): 35-39.

38. Liu Yang, Ma Xiangyu. The experience and enlightenment of student affairs management in American firstclass universities [J]. First-class universities and higher education, 2021(8): 49-54. 